\title{
PLATÓN. Lísis. Traducción, introducción y notas de Ivana Costa. Buenos Aires: Colihue Clásica, 2019. ISBN 978-950-563-098-1
}

Antonio Carlos Luz Hirsch*

Recebido em: 26/01/2020

Aprovado em: 04/03/2020
*Doutor em Filosofia pela Universidade Federal do Rio de Janeiro e membro do PRAGMA, Programa de Estudos em Filosofia Antiga, UFRJ. aclhirsch@gmail.com
$\mathrm{O}$ interesse pelo Lísis de Platão tem crescido nas últimas décadas e a importância deste curto (e críptico) diálogo tem sido sublinhada cada vez mais enfaticamente por parte dos estudiosos. Desde a publicação do artigo seminal de H. G. Gadamer, publicado originalmente em 1972, tem-se discutido cada vez mais o sentido deste texto. Ao que indica a produção recente, encontra-se estabelecido um debate em plena ebulição. O surgimento de novas versões vernaculares, como a que temos em mãos, deve ser percebido como signo da busca empreendida pela comunidade acadêmica na atualidade com objetivo de esclarecer o significado filosófico desta obra.

O volume aqui em questão nos propõe uma nova versão para o castelhano a cargo de Ivana Costa, platonista argentina da nova safra de professores de Filosofia Antiga do país vizinho e já conhecida no meio dos Estudos Clássicos no Brasil. De início, chamam atenção o extenso ensaio introdutório, as numerosas notas que acompanham a tradução do texto e a longa lista de referências bibliográficas. A autora nos conta que a extensão do ensaio de apresentação e o número elevado de notas de rodapé têm origem na dificuldade que ela mesma enfrentou para compreender o texto. Ela menciona que seu entendimento da obra, bem como as soluções finais da tradução, contaram com a interlocução mantida com Marcelo Boeri, professor argentino radicado no Chile, autor de uma tradução publicada na mesma coleção da Editora Colihue dedicada ao Cármides.

Na leitura das primeiras páginas da "Introdução" percebemos que a dificuldade de compreensão do diálogo experimentada pela autora, longe de ser uma exceção, se estende à grande maioria, senão à 
totalidade dos estudiosos. O ensaio tem o cuidado de historiar a recepção da obra em questão, de forma a evidenciar a intenção de abordá-lo metodicamente, tendo como perspectiva a pouca atenção que a dimensão filosófica do Lísis obteve de seus leitores. O texto escrito por Ivana Costa deseja sublinhar como sucessivas gerações de estudiosos abalizaram o Lísis tendo como pressuposto o fracasso da tentativa de definir o ser da philía ou atribuindo ao diálogo a apologia de uma espécie de amor egoísta e interesseiro. Em verdade, como salienta o estudo, muitos dos preconceitos referentes ao Lisis têm origem em uma leitura do diálogo a partir de conceitos de Aristóteles, que retoma a argumentação de Sócrates no texto traduzido por nossa colega argentina em seus escritos morais.

Ao contrário da crítica que dominou a interpretação do diálogo desde o final do século XIX até meados da segunda metade do século XX, a autora se empenha em salientar a natureza altruísta do texto de Platão, opondo-se frontalmente ao argumento daqueles que sustentam haver no Lísis uma percepção utilitarista da amizade. A pesquisadora se propõe a investigar como somente em uma leitura parcial se pode dar ensejo a tal interpretação. Ela acredita na existência de um "processo de redescobrimento" do Lisis ante o pano de fundo arqueológico da interpretação negativa, senão cética, do diálogo. De fato, o Lisis vem a ser uma das obras menos lidas e consequentemente menos estudadas do corpus platonicum, uma realidade que tende a se reverter nos tempo atuais.

A estudiosa destaca que, desde a escola alexandrina, o diálogo recebeu o subtítulo "sobre a amizade" (perì philias). Desde então, foi lido como uma obra cujo escopo consiste em estudar a noção de philía, mais precisamente, o modo como a amizade se estabelece entre dois ou mais. A autora tem o cuidado de salientar que o texto em nenhum momento registra a pergunta "o que é a philía?", o que vem a ser um indício seguro de que o seu propósito primeiro não reside exatamente em buscar estabelecer o conceito da amizade, mas sim conhecer sua natureza, o que, para Platão, implica em uma investigação específica e de ordem mais abrangente. Em lugar do que se desenharia como um enfrentamento direto e logicamente orientado do escopo do diálogo, o Lisis expõe dramaticamente, e de maneira fictícia, como Sócrates teria um dia se aproximado de jovens da elite ateniense com a disposição de dialogar e defender que, sem phrónesiss, não é possível existir philía. Essa narrativa obedece à estratégia discursiva do filósofo e deve ser estudada, como no caso presente, como integrante do modo de ser da filosofia.

O texto anteposto à tradução contém uma análise da argumentação do diálogo regrada por duas diretrizes fundamentais. A primeira delas consiste em sinalizar que a obra não pode ser corretamente compreendida ignorando-se o nexo causal entre o tema central, a philía, e a política. Ivana entende que a conexão é apresentada ao leitor por via da elaborada dramaticidade empregada por Platão. O ensaio enfatiza repetidas vezes que, especialmente no Lísis - faltou dizer em toda obra de Platão - dramaticidade e filosofia são coalescentes. Temos o vício de atribuir ao drama apenas a função de dar suporte à especulação teórica em torno do assunto escopo do texto, mas, segundo a tradutora nos alerta, devemos entendê-lo como um meio pelo qual o filósofo pensa e, por conseguinte, escreve.

Assim, a argumentação lógica direcionada à investigação do ser da philía se encontra irremediavelmente associada à noção de que a instituição amizade está na raiz da cidadania 
e da educação necessária à participação efetiva nas assembleias que regem "as coisas da cidade". Os personagens, com a exceção de Sócrates, são extremamente jovens de modo que o anseio em aprender como se fazer amigos coincide com o desejo (e a imposição) de aprender a virtude própria do cidadão.

A autora estuda a junção entre o tema central do diálogo e a paideía requerida pela cidadania, entendendo que o escopo do diálogo advém de uma experiência linguística e institucional que talvez não possamos compreender inteiramente. Ivana tem como ponto de partida a questão de que, para os personagens retratados por Platão, essa experiência constitui uma condição mesma e, assim sendo, um aspecto fundamental da ação política. A estudiosa toma como fator indicador desta realidade a passagem da Carta VII na qual Platão explicita que a amizade constitui um elemento constitutivo da ação política quando afirma no passo 325 desse documento que não poderia agir na cidade áneu phílon andrôn kaì hetetaírōn pistôn (sem amigos e companheiros confiáveis). Além disso, o texto remete o leitor ao estudo capital de M. W. Blundell, Helping friends and harming enemies. A study in Sophocles and in Greek ethics, publicado em 1989 e voltado precisamente para a compreensão do caráter político da amizade desde tempos arcaicos.

Paralelamente, Ivana Costa se dedica a investigar como a pederastia grega, tida como instituição política e social, está no centro da preocupação do filósofo quando percebe a necessidade de ressignificar filosoficamente a noção de philía. Se em tempos heroicos a pederastia pode ser apontada como modelo para a a iniciação da vida adulta, portanto, como paradigma dos valores da vida cívica, a investigação de Ivana mostra que, na época clássica, é possível detectar a deterioração do código de conduta envolvendo amante (erastếs) e amado (erómenos). O ensaio estuda o reflexo da decadência da pederastia na prosa de Ésquines, Xenofonte e sobretudo da comédia aristofânica. A autora comenta que, enquanto outros se empenhavam em estabelecer uma fronteira entre o amor pederasta nobre, conforme o código instituído pela tradição, e uma forma forma vulgar de relacionamento entre homens e rapazes mais novos, na qual o erómenos se transformaria numa espécie de profissional do sexo, Aristófanes diverte o público do teatro mesclando-os (cf. Aves, 703-8). Ivana Costa sublinha que a época de Platão era marcada pelo questionamento a respeito da fronteira entre uma ligação amorosa homossexual, regrada pela beleza e pela virtude, e uma relação perversa, perpassada pela obtenção de favores e pelo interesse, e ressalta que, com o Lisis, o filósofo toma parte da discussão então em curso.

De fato, Platão insere-se na discussão envolvendo a crise relativa à prática do homoerotismo no seu tempo dirigindo uma crítica sobretudo aos poetas que, segundo o Lisis deixa transparecer, não souberam dizer corretamente em que consiste e como precisamente se instaura o laço de amizade, berço da relação erótica entre varões, portanto, princípio da educação cívica e da vida política. O estudo introdutório explora a conexão estabelecida pelo texto entre a especulação teórica e a vida política como um alicerce do Lísis e, por extensão, da reflexão filosófica. No entender do ensaio, sem considerar este vínculo, o leitor perde-se na retórica que se interpõe como cenário no qual o discurso filosófico se erige, mas com o qual jamais se confunde. 
A autora desta maneira se afasta daqueles intérpretes que encontram motivos textuais para analisar o diálogo como uma peça na qual o autor retrata o Sócrates histórico a manipular, de maneira inepta, recursos discursivos próprios dos professores de seus jovens interlocutores, especialistas em erística. Quando Sócrates se dirige a Hipótales, ele anuncia estar interessado em examinar sua diánoia (205b2), sem se importar com os elogios em verso e prosa escritos pelo rapaz. O posicionamento de Sócrates distingue o campo de interesse da filosofia, em contraposição aos lógoi que os ensinavam como conquistar um amado.

Aqui torna-se preciso um parênteses para se lembrar de que a philía, como laço afetivo e sustentáculo da vida política, constitui um elemento básico da composição da palavra philosophía, termo utilizado por Platão para nomear o gênero de discurso que fala por meio da dialética. A ressignificação da noção de philía proposta no Lisis insere-se, desta forma, na estratégia do autor em fundar um gênero do lógos no qual a philosophía possa, enfim, vir a existir. Quando Platão faz Sócrates dizer que, sem se tornar sophós, o jovem Lísis jamais será livre e desejado como filho ou amigo (210d), ele está igualmente procurando ressignificar o segundo termo que, junto a philía, forma o nome que confere identidade ao modo como ele mesmo fala. Isto é, construindo diálogos nos quais a sophía se encontra ancorada por laços de philía. Portanto, o esforço de ressignificação da philia e da sophía presente no Lísis se sujeita ao projeto de fundação da philosophia como gênero.

Ivana Costa chama atenção para o fato de um número expressivo de comentadores classificar o Lisis como um diálogo proléptico, ou seja, como um escrito de exortação à filosofia, a qual se encontraria efetivamente desenvolvida em outro lugar, como no Banquete, na República e no Fedro. Ivana compreende o Lísis de modo autônomo, evitando lê-lo como uma obra de juventude marcada pela especulação teórica preambular, cujas ideias, então mal desenvolvidas, ganham tratamento mais rigoroso e apropriado em obras presumivelmente escritas posteriormente. A defesa da independência teórica do Lísis se estende ao entendimento de que o desenvolvimento atribulado dos argumentos e o encerramento supostamente aporético não tipificam um defeito de ordem teórica ou uma obra incipiente.

Os primeiros leitores de Platão não se importaram pontualmente com o matiz aporético do texto, coube à crítica moderna apontar o desconforto pela ausência de uma definição de philía. É de se notar que o mal-estar em relação ao final inconclusivo do Lísis se origina no fato de o diálogo não apresentar uma definição em moldes aristotélicos. Ivana Costa escreve: "desde tempos imperiais o caráter aporético do Lísis se encontrava eclipsado pela presunção de que havia uma verdade que o diálogo contribuía para 'dar à luz' em seus leitores". De acordo com o estudo apresentado pela estudiosa, a mesma visão permaneceu entre os primeiros leitores renascentistas do diálogo, que redescobriram o Lísis no século XV. Ela informa ainda que a primeira edição do texto grego da obra apareceu em Veneza, em setembro de 1513, na editora de Aldo Manuzio.

Quanto à tradução propriamente dita, Ivana Costa prova ser uma tradutora consciente e, sobretudo, não impositiva. Em uma passagem de crucial importância para a exegese do diálogo e, de certa maneira, de forma mais abrangente, para a compreensão do pensamento de Platão como um todo, a professora expõe sua hesitação como intérprete. 
Ela afirma ter entendido o texto em determinada direção, enquanto assinala explicitamente que uma segunda leitura vem a ser linguisticamente correta e filosoficamente possível (senão desejável). Refiro-me ao diálogo que Sócrates mantém com o jovem Lísis no início do texto (207d6-210d8). Em certa altura (210d1), como já referido, o protagonista e narrador diz que somente tornando-se sophós (sophòs génèi) o rapaz se tornará útil e bom, passando a ser amigo, íntimo de todos, e livre.

Ora, a pergunta crucial que o tradutor (e intérprete) deve fazer a essa altura recai sobre o que Sócrates está exatamente querendo dizer quando prescreve a sophía como condição indispensável para a aquisição de amigos e "íntimos", inclusive para a aquisição da amizade dos próprios pais, visto que Platão entende que o vínculo sanguíneo não basta para que exista amizade entre pais e filhos. Ivana revela-se então extremamente delicada. Ela enuncia sua opção pela acepção "epistêmico-cognitiva" da noção de sabedoria em questão neste passo. Ela julga, em adesão à opinião de boa parte dos estudiosos (uma exceção notável vem a ser H. G. Gadamer), que a sabedoria posta em questão por Sócrates versa sobre a necessidade de conhecimento.

No entanto, ela comenta não ser esse o único entendimento possível, nem a única tradução cabível. A tradutora informa que Sócrates recomenda que o jovem se torne sophós em um contexto regido pelo verbo phronéo, traduzido por "ser sensato" ou "ser inteligente" (n. 40, p. 19), o que, em seu entender, dá a entender que a sophía prescrita ao jovem possui um matiz de ordem "prática". O phroneîn, destaca, domina toda a passagem e confere à sabedoria recomendada ao jovem uma conotação "cognitiva-prática" (n. 47, p. 22). Tratase, consigna a autora, não somente de "ser sábio" no sentido de deter um conhecimento mas de "ser sensato", "entender", "pensar". Donde devemos estar atentos para a questão de que a recomendação diz respeito a um saber inserido em uma "situação". Trata-se, fundamentalmente, sublinha ela nas notas ao texto de número 40 e 42 , de um saber ou um compreender "para a ação".

Ivana registra uma alternativa a sua escolha consignando em nota de rodapé uma segunda possibilidade de tradução (e entendimento) do texto de Platão. Tendo traduzido as linhas do passo $210 \mathrm{~d}$ para castelhano conforme transcrevemos a seguir, ela anota uma variante, transcrita aqui em itálico colocado por nós. Temos, conforme salienta a autora (n. 48, p. 22):

“¿es possible, Lisis, tener un saber signicativo en lo que aún no se sabe?

¿es possible, Lisis, una sensatez sobresaliente (méga phroneîn) en aquillo en que uno no es sensato (mếpō phroneîn)?”

E, em seguida:

"Por tanto, si tú precisas un maestro, todavía no eres sabio.

Por tanto, si tú precisas un maestro, todavia no eres sensato (phroneîs)."

Por fim:

"- Entoces, si todavía no sabes, tampoco eres un hombre con un saber superior. 
- Entonces, si todavía no eres sensato (áphrōn éti), tampoco tienes una sensatez. sobresaliente (oud'ára megalóphrōn)."

A nuance anotada pela tradutora dá a chance ao leitor de compreender que a sophía prescrita por Sócrates vai além de um saber propositivo, que pode ser ensinado. Quando Sócrates é introduzido a Lísis, Platão registra que este, baseado apenas na visão (tò eîdos, 204 e 6), distingue o jovem considerando-o kalós te kagathós (207a3), como que adivinhando que o menino possuía certa familiaridade com o que é agathós e, por esta razão, possuía condições de, tornado-se sábio, agir bem. Embora Ivana Costa não desenvolva o tema e tenha sobretudo tomado uma decisão diversa quanto à tradução e à compreensão do texto, suas anotações no rodapé revelam uma tradutora zelosa e permeável.

Devemos atentar para o fato de que a conversa entre Sócrates e Lísis tem para o narrador um valor modelar. O modo como um amante deve (khrế) falar (légein) ao amado constitui um tópico central do diálogo, anunciado logo na abertura (205a1-2). Quando esse diálogo chega a seu fim, Sócrates torna manifesto que passou por sua cabeça consignar de maneira expressa que ali estava configurado como se deve (khré) conversar com o jovem amado (toîs paidikôis dialégesthai), mas explica que, dada a circunstância, se conteve e guardou para si suas palavras (210e3-211a1). O que Sócrates silencia constitui um comentário de ordem filosófica de importância crucial - essa passagem revela que aqueles que são amigos têm um modo de falar específico, não somente entre si, mas também com outros (pròs autòn è pròs állous, 205a2) e que o dialégesthai e o phroneîn são o que difere a filosofia da erística, em outras palavras, o que torna dois ou mais "amigos".

O Lísis caracteriza-se pelo estudo e utilização em nível lexical, semântico e pragmático das possibilidades discursivas sobre "as coisas do amor" (tà erōtiká), área em que Sócrates, contrariamente à sua difundida declaração de ignorância, se pronuncia um expert (204c1-3). O estudioso, como Ivana Costa, que tira vantagem da riqueza discursiva, para não dizer do verdadeiro manancial linguístico, em torno do fenômeno da philía está mais perto de compreender o enigmático tratado sobre o erotismo humano que se configura neste pequeno diálogo. Esse pesquisador beneficia a si mesmo e a seus leitores com o entendimento de que, apesar de não existir um significado unívoco para a as noções abordadas pelo filósofo nessa obra, o tradutor deve fazer escolhas e verter os termos gregos empregados no texto de partida para o idioma de chegada.

Não seria preciso mencionar que, no tempo em que o diálogo foi escrito, a philía e noções correlatas não se encontravam fixadas conceitualmente, isto se as terminologias em torno das relações de afeto em algum momento na Antiguidade tiveram o seu significado estabelecido de maneira rígida e rigorosa. Assim sendo, Ivana Costa opta por notas explicativas (148 ao todo) que guiam o leitor num caminho sinuoso. O volume conta com um projeto gráfico que facilita a leitura dessas notas pois as mantém ao pé de página, evitando o atropelo que ocasiona a consulta a notas no final do texto, como é bastante usual nesse tipo de publicação. 
Ivana deixa manifesto que phílos e phileîn empregam-se no sentido ativo (amante; amar) e passivo (amado; ser amado), o que exige da tradutora deixar claro em cada ocorrência o significado da flexão nominal empregada pelo autor.

Para mencionar mais um exemplo de como nossa colega portenha elabora suas escolhas como tradutora, em outra passagem ela decide pelo emprego do sintagma em castelhano "experimento un enorme deseo erótico por possuir amigos", dando vazão à força e à clareza semântica da expressão em grego tôn philôn ketêsin pány erōtikôs. O texto diz claramente que Sócrates se considera possuído pelo desejo erótico de adquirir amigos e a tradução da autora deixa perfeitamente transparecer no idioma de chegada toda a crueza da língua de partida.

O passo faz constar um deslocamento do âmbito do apetite para o desejo erótico, próximo da paixão sexual cuja presença fica sugerida, jamais sendo explicitada. Em verdade, há um duplo deslocamento no texto grego, Sócrates primeiro declara: ek paidòs epithymôn ketématos (“desde criança desejo algo"), para em seguida afirmar ser pány erōtikôs ("muito apaixonado”) pela aquisição de amigos e logo após dizer que entre outros bens escolheria (bouleloimèn) um "amigo bom" (phílos agathós). A passagem tem a virtude de, em poucas linhas, fazer uso de boa parte do léxico em torno da philía. Ivana Costa a lê como um ponto de contato com a comédia de Aristófanes, na qual listas de bens desejados pelo erómenos aparecem com frequência. Por outro lado, temos que levar em consideração que há algo de sério no que é dito aqui, pois a passagem se conecta com a declaração inicial de Sócrates de que ele, por uma dádiva divina, sabe reconhecer (gnônai) aquele que ama e aquele que é amado (204c2-3).

Exemplos como esses se multiplicam, proporcionando ao leitor, em especial aos estudantes dos textos de Platão ainda não familiarizados com o idioma em que foram produzidos, a chance de experimentar certo estranhamento inerente ao modo mesmo como o filósofo utilizou a língua grega para escrever sobre os diversos temas que mereceram sua reflexão, dentre eles, o próprio evento discursivo.

Diante de tudo o que foi dito até aqui, nos cabe saudar vivamente a publicação do trabalho de Ivana Costa, tendo como base o diálogo platônico Lisis. Sua leitura será de muito préstimo tanto ao mais exigente estudioso dos diálogos, como aos estudantes que primeiro tomam contato com a obra do filósofo ateniense. Como o texto da contracapa do volume que temos em mãos manifesta, este diálogo, diferentemente de textos como o Alcibiades Primeiro, que na Antiguidade foi recomendado como primeiro texto a ser lido na ordem de leitura dos escritos de Platão por parte daqueles que iniciam no estudo de sua filosofia, dada a sua riqueza especulativa, está longe de ser um diálogo para principiantes. Que a "Introdução" e as abundantes notas escritas pela autora sirvam como guia seguro, ou mesmo fio de Ariadne, para que o leitor mova-se no tópos labiríntico construído neste diálogo. Que os comentários e o estudo criterioso de nossa colega (e amiga!) argentina se torne uma peça relevante no processo de redescoberta deste controverso tratado filosófico. Que no curso de sua leitura o leitor possa avaliar se não tinham razão os comentadores da Antiguidade para os quais a natureza aporética do Lísis era senão mais um signo do gênero filosófico criado por Platão. 